\title{
A Numerical Analysis on the Behavior of Single Battered Pile under Pullout Loading
}

\author{
Mais S. Al-Tememy ${ }^{1, a}$, Mohammed A. Al-Neami ${ }^{1, b^{*}}$, and Mohammed F. Asswad ${ }^{1, c}$ \\ ${ }^{1}$ Civil Engineering Department, University of Technology-Iraq, Baghdad, Iraq. \\ amais.salim93@gmail.com, b40008@uotechnology.edu.iq, 40083@uotechnology.edu.iq
}

\begin{abstract}
Batter or raker piles are piles driven at an inclination with a vertical to resist large inclined or lateral forces. Many structures like offshore structures and towers are subjected to overturning moments due to wave pressure, wind load, and ship impacts. Therefore in such structures, a combination of the vertical and batter piles is used to transfer overturning moments in compression and tension forces to the foundation. This paper presents a three-dimensional finite element analysis using PLAXIS 3D software to study the battered pile's behavior under the effect of pullout load. Several variables that influence the pile tension capacity embedded in sandy soil are investigated. The pile models are steel piles embedded in the dense sand at different batter angles $(0,10,20$, and 30) degrees with two embedment ratios, L/d (15 and 20). To clarify the pile shape's influence on a pullout capacity, two shapes are used, a circular pile with a diameter equal to $20 \mathrm{~mm}$ and a square pile with a section of $15.7 \times 15.7 \mathrm{~mm}$. These dimensions are chosen to achieve an equal perimeter for both shapes. The numerical results pointed that the pile pullout capacity increases with the increasing of the batter angle and embedment ratio, and the maximum values are marked at a batter angle of $20^{\circ}$. The shape of the bending moment profile is a single curvature, and the peak values are located approximately at the midpoint of the battered pile, while a zero value is located at the pile tip and pile head.
\end{abstract}

Keywords: Batter pile; pullout capacity; finite element analysis; PLAXIS 3D.

\section{Introduction}

In marine structures, tall chimneys, towers, and bridges are usually subjected to overturning moments generated by the berthing ship's impact, by the pull from mooring ropes and waves, currents, and winds and floating ice. These effects will transfer to the foundation of structure as a pullout load on some elements and a compression load on the others [1]. So, when piles are required to resist the forces causing the overturning or sliding of structures, the design against lateral forces and uplift forces becomes necessary. A vertical pile has a meager resistance; therefore, vertical piles and batter piles combination is used. Little numerical and experimental studies have been devoted to study the batter pile behavior under pullout loading. Hanna and Afram [2] carried out an experimental study to investigate single vertical and batter piles' pullout capacity in sandy soil subjected to an axial load. The results showed the shaft resistance was unaffected by the pile inclination. Also, to predict the ultimate pullout capacity of a single batter pile inclined with an angle $\alpha$ in the sand, the following formula was suggested:

$$
\mathrm{P}_{\mathrm{u} \alpha}=\mathrm{P}_{\mathrm{u}} \cos \frac{\alpha}{2}
$$

Where:

$\mathrm{P}_{\mathrm{u \alpha}}=$ ultimate pullout capacity of the inclined pile.

$\mathrm{P}_{\mathrm{u}}=$ ultimate pullout capacity of the single vertical pile, and

$\alpha=$ inclination angle of a pile with vertical $\left(0^{\circ} \leq \alpha \leq 30^{\circ}\right)$.

Atici [3] developed a 3D numerical model to determine the single battered pile's shaft resistance in sandy soil under uplift and compression loadings using ABAQUS version 6.6. He concluded that the shaft resistance is highly dependent on the diameter, length, and shape of the pile, angle of friction interface, and conditions of initial loading. Bose and Krishnan [1] performed the experimental tests 
on vertical and batter model piles constructed in sand subjected to pullout loads to investigate the influence of pile inclination, pile cross-section, and surface characteristics. The results showed that the net ultimate pullout capacity increases with an increase in length to diameter ratio and batter angle. Also, for piles of varying shapes with a constant volume, a circular pile resists more uplift force than the square or rectangular piles. Nazir and Nasr [4] carried out an experimental study to evaluate the influence of the variables parameters on the battered pile's ultimate shaft resistance. The study showed the influence of pile inclination, pile shape, pile slenderness ratio, and the unit weight of sand on the ultimate axial pullout capacity of vertical piles and batter piles. They showed that when batter angle and slenderness ratio increase, the ultimate pullout capacity of a battered pile embedded in the dense sand was increased, and the circular pile is more resistant to pullout forces than the square and rectangular pile shape. Gaaver [5] investigated the effect of the pile's embedment depth on the uplift capacity of the single pile and pile groups constructed the sand. The results concluded that for single piles under uplift loading, the net uplift capacity mainly dependents on the (L/d) ratio. Hazzar et al. [6] carried out a three-dimensional finite-difference analysis using FLAC3D to study the influence of the inclination angle on battered piles' behavior under the lateral load. The results showed that the batter piles' lateral capacity is affected by the sign and of the batter angle.

Al-Neami et al. [7] used 32 steel solid pile models to examine the effect of five batter angles $\left(0^{\circ}\right.$, $10^{\circ}, 20^{\circ}, 30^{\circ}$, and $40^{\circ}$ ) on the ultimate load capacity of a single pile model. They stated the increasing battered angle would increase the pile capacity until reaching the peak value at $20^{\circ}$, thereafter the resistance began to decrease. Naveen et al. [8] introduced a laboratory study to study the influence of the batter angle, pile group configuration, and influence of sand density on ultimate uplift resistance. It was found that the increase in relative density of soil and batter angle causes an increase in the uplift capacity of a single pile and group piles. Sabbagh et al. [9] studied the effect of pile group arrangement and piles' inclination angle on the lateral response of the piles' group. The study showed that batter angle and pile group arrangement affect the behavior of the pile in a group. Gebresilassie [10] presented a three-dimensional finite element analysis using PLAXIS software to study the behavior of a batter and vertical pile subjected to the lateral, axial, and inclined loads. The study attempts to examine the effect of batter angle on its ultimate lateral and axial load capacity. It noted that when the batter angle increases, a pile load-carrying capacity increased until the angle reaches $20^{\circ}$; after that, the resistance begins to decrease. The current theoretical work focuses on the batter pile behavior under pullout load because the data are very limited; therefore, this study will present the single batter pile behavior with various parameters. This paper involves 3D finite element analysis, FEA. A 3D PLAXIS software has been carried out to depict the effect of many variables on the pullout capacity of vertical and batter piles embedded in the dense sand. A numerical program is used to examine the effect of batter pile angle, embedment ratio, and the effect of the pile shape on the battered pile's behavior.

\section{Numerical Model}

Validation of Numerical Model. In this paper, the experimental study carried out by Nazir and Nasr [4] on vertical and batter pipe pile under axial pullout are used to verify the numerical software results. Tests were carried on piles of mild steel hollow pipes with a $25 \mathrm{~mm}$ outside diameter and $1.5 \mathrm{~mm}$ wall thickness installed in dense sand with an embedded ratio (L/d) equals 15 . The unit weight of soil is $14.95 \mathrm{kN} / \mathrm{m}^{3}$, and the internal friction angle equals $30.5^{\circ}$. The soil is modeled using the MohrCoulomb model and the pile as volume pile, which is discretized with hollow elements. Figure 1 shows a good agreement between the load-displacement curves for the experimental and numerical analysis. It could be concluded that the numerical results can be adopted. 


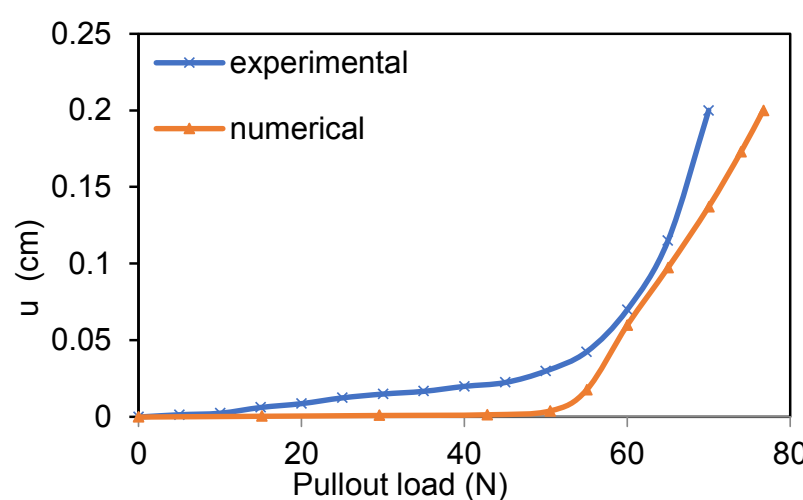

(a) Vertical pile

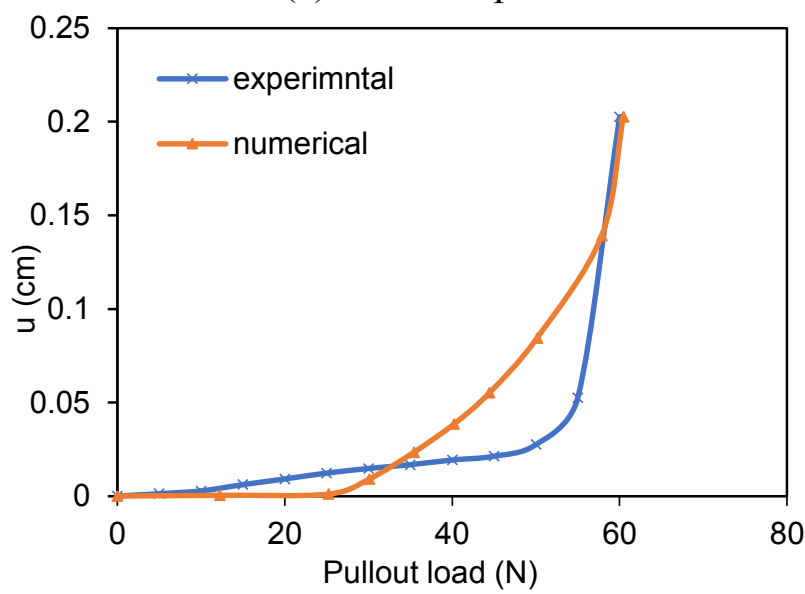

(c) Batter $20^{\circ}$

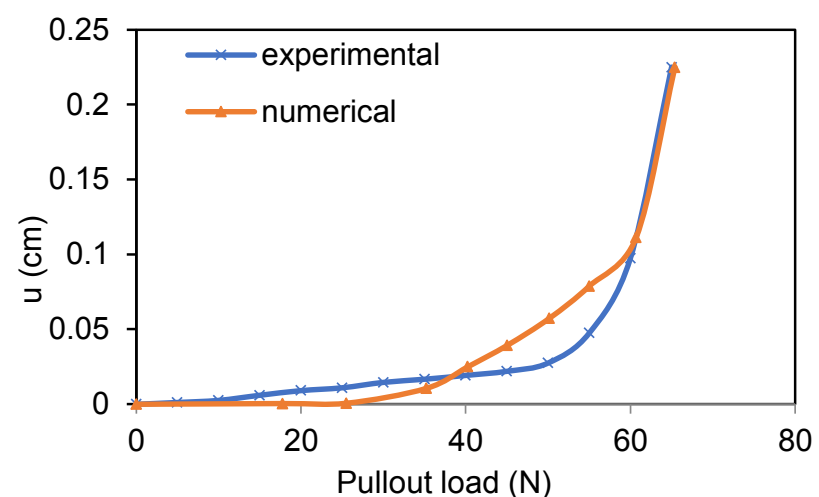

(b) Batter $10^{\circ}$

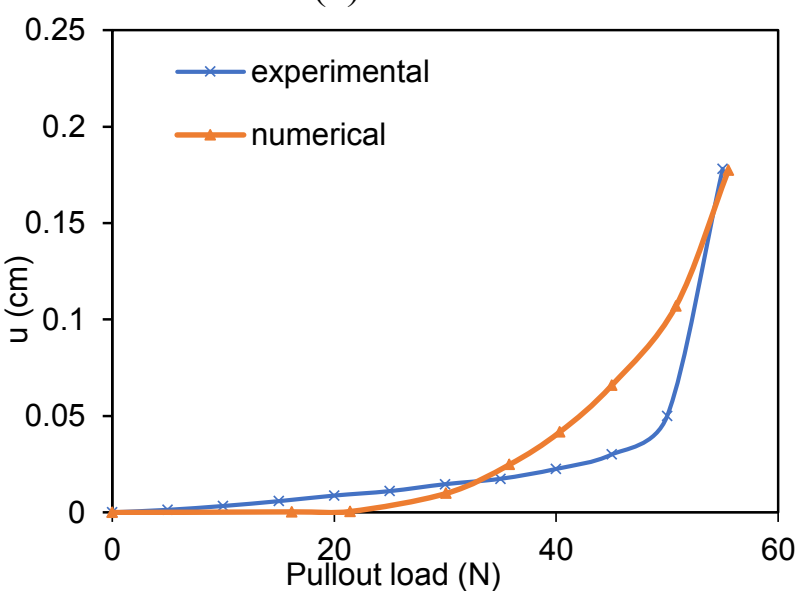

(d) Batter $30^{\circ}$

Figure 1. Validation of software used.

Soil Modeling. The numerical studies are carried out in dense sand. The soil has been modeled using the Mohr-Coulomb constitutive model. The Mohr-Coulomb model is widely used in FEA of geotechnical engineering studies to simulate the soil's nonlinear behavior because of its sufficient accuracy, simplicity, and a reasonable number of model parameters [11]. In the current research, the main parameters of soil were taken from the experimental study carried out by Al-Neami et al. [12]. The soil parameters used in the numerical analysis are listed in Table1.

Table 1. Soil Parameters used.

\begin{tabular}{|l|c|}
\hline \multicolumn{1}{|c|}{ Soil properties } & Values \\
\hline Soil type & Poorly graded sand, SP \\
\hline Relative density $(\%)$ & 80 \\
\hline Specific Gravity, Gs & 2.66 \\
\hline Unit weight, $\gamma_{\text {dry }}\left(\mathrm{kN} / \mathrm{m}^{3}\right)$ & 18.7 \\
\hline Friction angle, $\phi$ & 40 \\
\hline Dilatancy angle, $\psi$ & 10 \\
\hline Modulus of elasticity $(\mathrm{MPa})$ & 40 \\
\hline Poisson ratio, $v$ & 0.3 \\
\hline
\end{tabular}

Pile Modelling. Vertical and batter piles are modeled using Embedded Beam Element with a unit weight of $78 \mathrm{kN} / \mathrm{m}^{3}$ and stiffness of $180 \times 106 \mathrm{kN} / \mathrm{m}^{2}$. The constructed pile is consisting of the beam elements with particular interface elements that give the interaction between the battered pile and the soil surrounding it. The numerical models were conducted on a solid steel pile model having a diameter equal to $20 \mathrm{~mm}$, and the corresponding $(\mathrm{L} / \mathrm{d})$ ratios were 15 and 20 . The elastic model describes the pile material, and the interface strength $\left(\mathrm{R}_{\text {inter }}\right)$ was taken as a manual and equal to 0.7. It is worth noting that prescribed displacements are special conditions imposed on a model to control 
the displacements at certain locations. When both prescribed loads and displacements are applied and active on the geometric entity, the prescribed displacement has a priority over the load during the calculation [13]. Therefore, the vertical upward displacement is kept constant and equals $0.2 \mathrm{~cm}$ as $10 \%$ of pile diameter, and the simulation was to obtain pullout loads and the load-displacement curves. Figure 2 shows the problem under consideration.
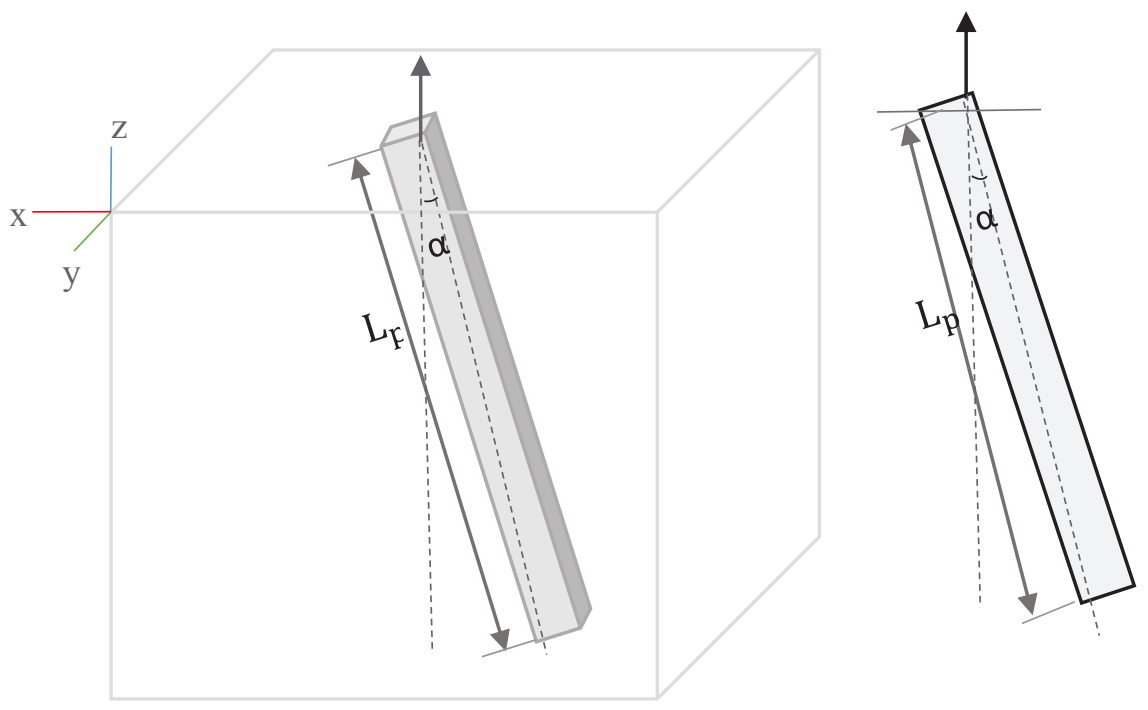

Figure 2. Problem under consideration: battered piles under pullout.

Generation of Mesh. To implement the finite element calculations, a geometry is divided into elements. Very fine meshes must be avoided because this kind of meshes will be lead to an excessive calculation time, so in this study, a fine mesh was used to obtain accurate numerical results. The PLAXIS 3D program uses the fully automatic generation of finite element meshes. The mesh generation process considers the stratigraphy of soil beside all structural loads, objects, and boundary conditions. The basic soil elements of the 3D FE mesh are the tetrahedral elements with 10-node. The domain of the model used in the analysis was $100 \mathrm{~cm}$ length, $75 \mathrm{~cm}$ width, and $70 \mathrm{~cm}$ in depth (Figure $3)$.

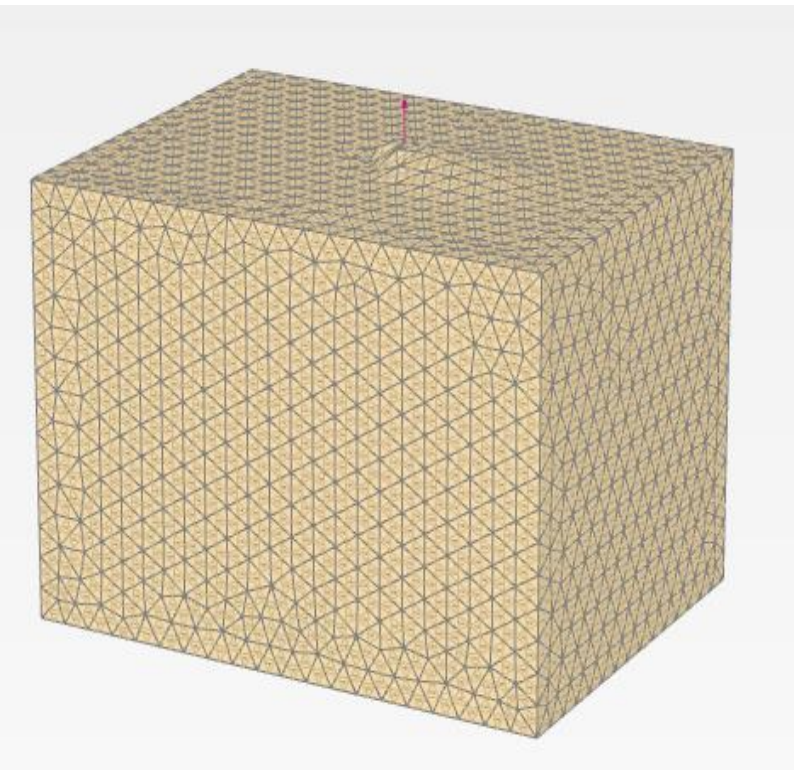

(a)

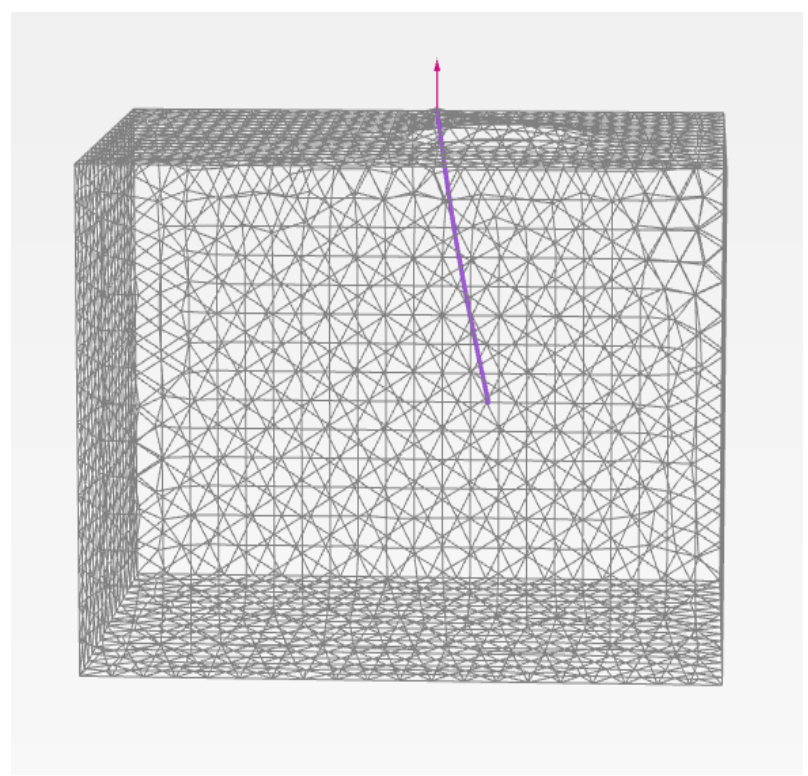

(b)

Figure 3. 3D FE mesh for the soil and pile: a) Soil material, b) An embedded batter pile, $\alpha=20^{\circ}$. 


\section{Results and Discussion}

Influence of Batter Angle on Pullout Capacity. Figures 4 to 7 show the pullout load-displacement curves for square and circular pile cross-section with L/D equals 15 and 20 respectively at batter angles which were studied. It can see that the ultimate pullout load of the battered pile embedded in the sandy soil with a relative density equaled $80 \%$ increases when the batter angle increased. In general, a battered pile has the ultimate pullout load more than the vertical pile, and the maximum values are marked at the batter angle equals to $20^{\circ}$. The linear relationship is evident at the beginning, then transformed to the nonlinear one. It is also noticed that the pullout load of the battered pile increases with an increase in the (L/d), and it found that the maximum pullout increases by two times and for both pile cross-sections (square and circular batter pile models) when L/D increases from 15 to 20. Also, the pullout for the circular batter pile is more than in the square batter pile.

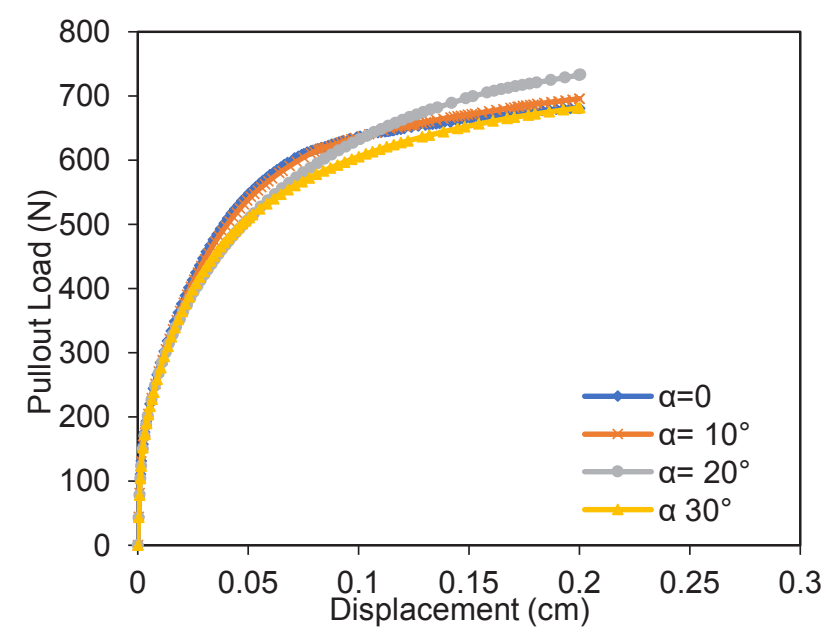

Figure 4. Pullout Load-displacement curves for circular vertical and batter pile $(\mathrm{L} / \mathrm{d})=20$.

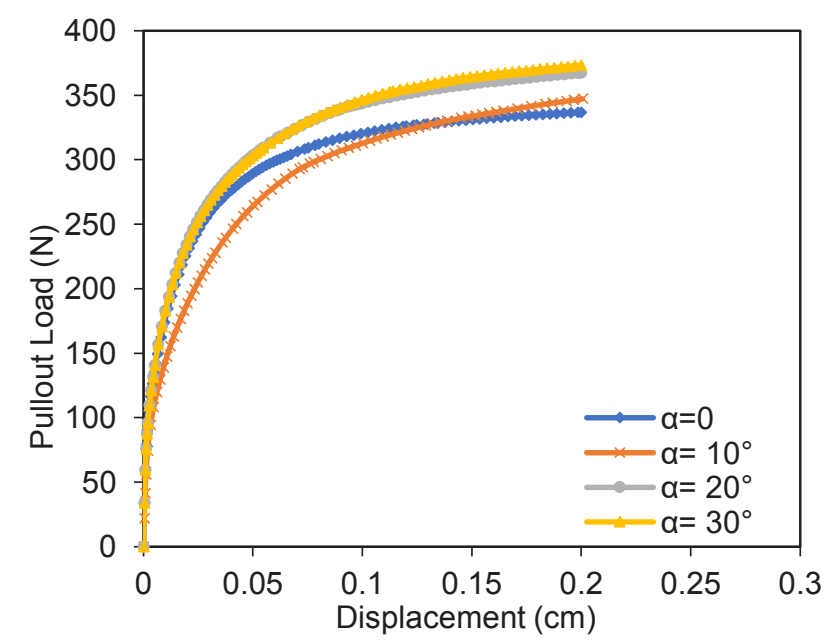

Figure 6. Pullout Load-displacement curves for circular vertical and batter pile $(\mathrm{L} / \mathrm{d})=15$.

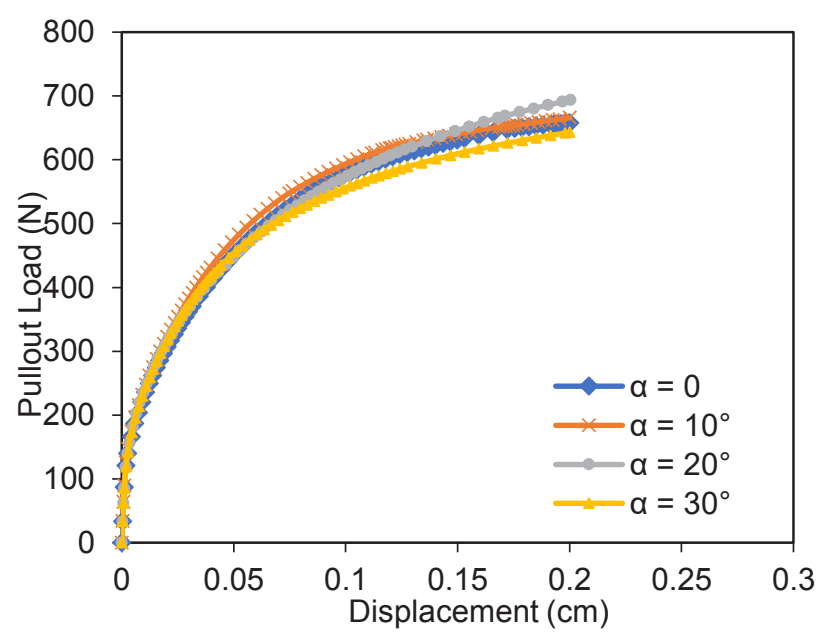

Figure 5. Pullout Load-displacement curves for square vertical and batter pile $(\mathrm{L} / \mathrm{d})=20$.

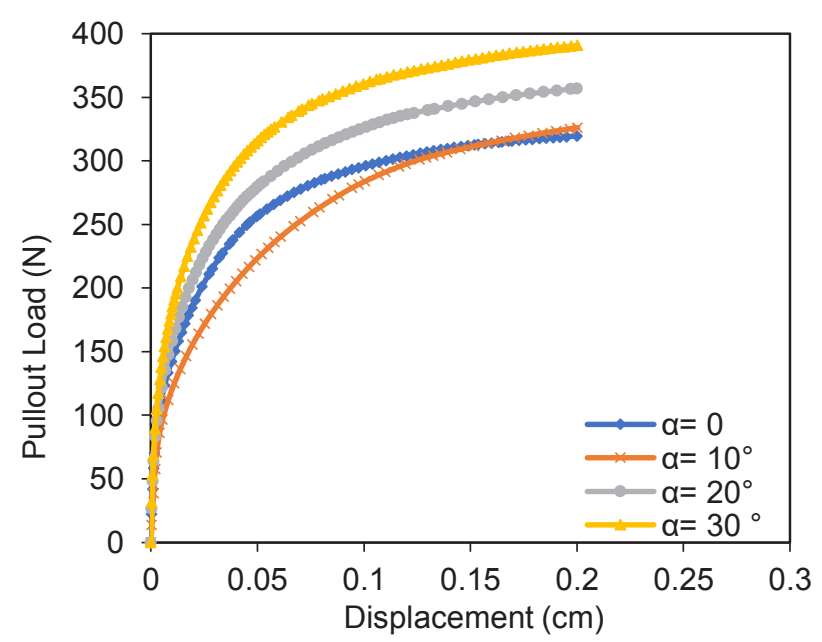

Figure 7. Pullout Load-displacement curves for square vertical and batter pile $(\mathrm{L} / \mathrm{d})=15$.

Pile Shape Influence. To clarify the influence of the pile's cross-section shape on the values of the vertical and batter pile pullout capacity, circular and square pile shapes were modeled with dimensions that give an equal perimeter. The circular pile has a $20 \mathrm{~mm}$ diameter, while the square pile has a cross-section of $15.7 \times 15.7 \mathrm{~mm}$. From the above figures, it can see that the pullout capacity of a circular pile increases by 2.8-6.1\% at (L/D) equals 15 and $4.3-8.5 \%$ at L/D equals 20 more than square pile shape, and this increase is due to changing radial stress around the perimeter of the pile 
which changes the earth pressure. This result is similar to the results obtained by Nazir and Nasr [4], who have stated that the pile has resistant more than the rectangular and square pile shape because, at the same load intensity, the pile with a circular shape has a head deformation smaller than the other shapes of the pile.

Influence of Embedment Ratio. In this study, two embedment ratios, L/D (batter pile Length over batter pile diameter) are investigated (15 and 20). Figures 8 and 9 illustrate the battered pile model's ultimate pullout load variation calculated at $0.2 \mathrm{~cm}$ displacement with various batter angles. It can be seen that the embedment ratio affects the pullout capacity of the battered pile; the pullout capacity of the battered pile increases with the increase in the embedment ratio L/d. At the same L/D, the pullout load increased with the increasing of the inclination angle until it reaches $\left(20^{\circ}\right)$; after that, a pullout load decreases or the increase is very small in its value. This variation occurred due to the increasing length of the pile, and hence, more skin friction resistance mobilized more pullout load. These findings are conjugated with results of references $[4,12]$.

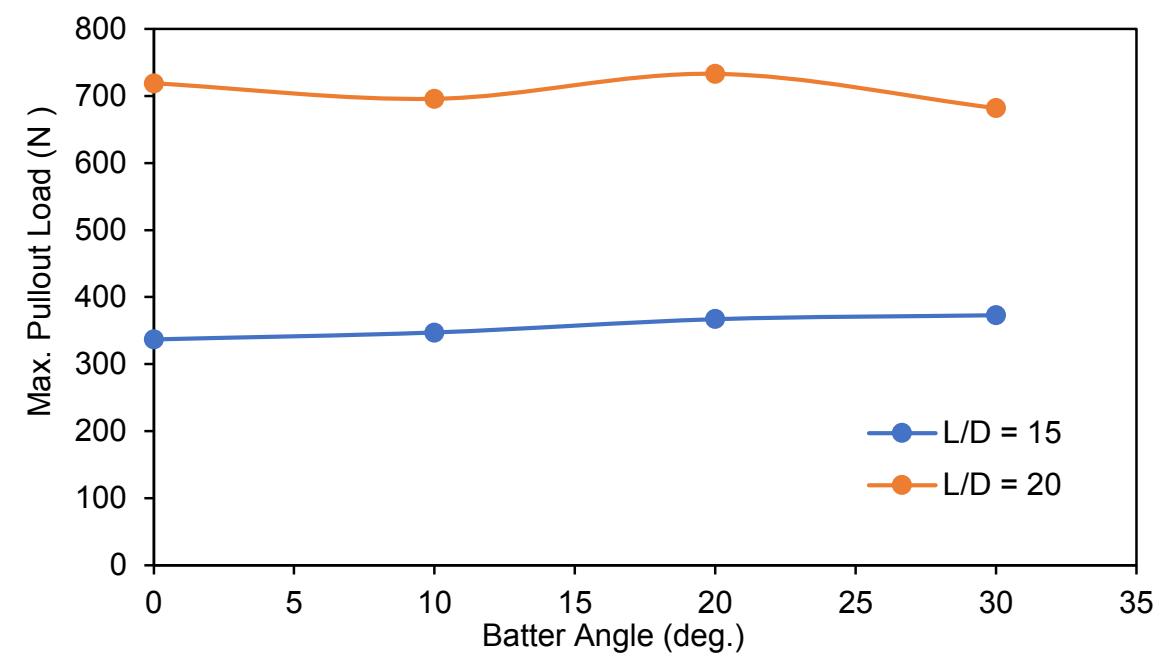

Figure 8. Ultimate pullout load variation of a circular batter pile at $0.2 \mathrm{~cm}$ displacement.

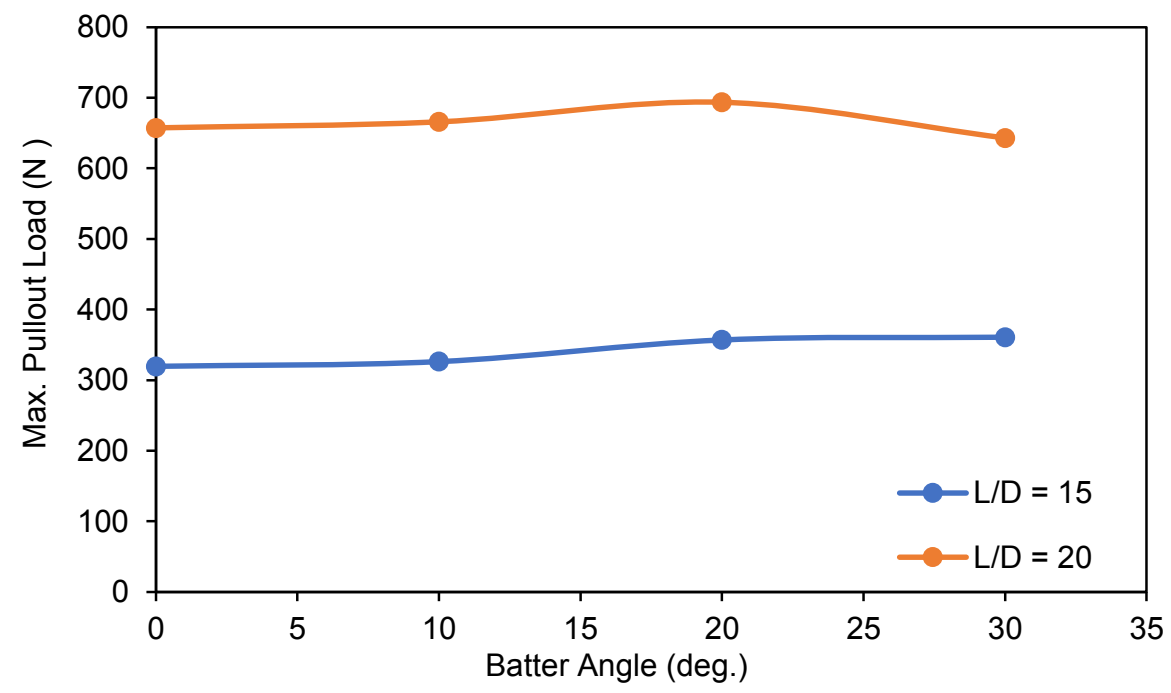

Figure 9. Ultimate pullout load variation of a square battered pile at $0.2 \mathrm{~cm}$ displacement.

Variation of Bending Moment. In the pile cross-section design, it is necessary to know the maximum bending moment's value and location along the pile length. Figures 10 and 11 show the bending moment distribution along the pile shaft with different batter angles. It is cleared that the bending moment increases with the increase in the batter angle. The profile of bending moment is a single curvature shape for all batter angles and bending moment values for a circular pile shape are higher than the square pile shape. It can be observed that the bending moment increased with the 
increasing of inclination angles and a zero value of moment at both pile tip and pile head while the peak bending moment is pointed approximately at a midpoint of batter pile. Also, the embedded ratio has less effect on the values and distribution of bending moment. This distribution shape of bending moment along the single pile may be returned to the load transfer mechanism, which developed along the pile length and surrounding soil which causes a change in the friction bonds at the points along pile length.

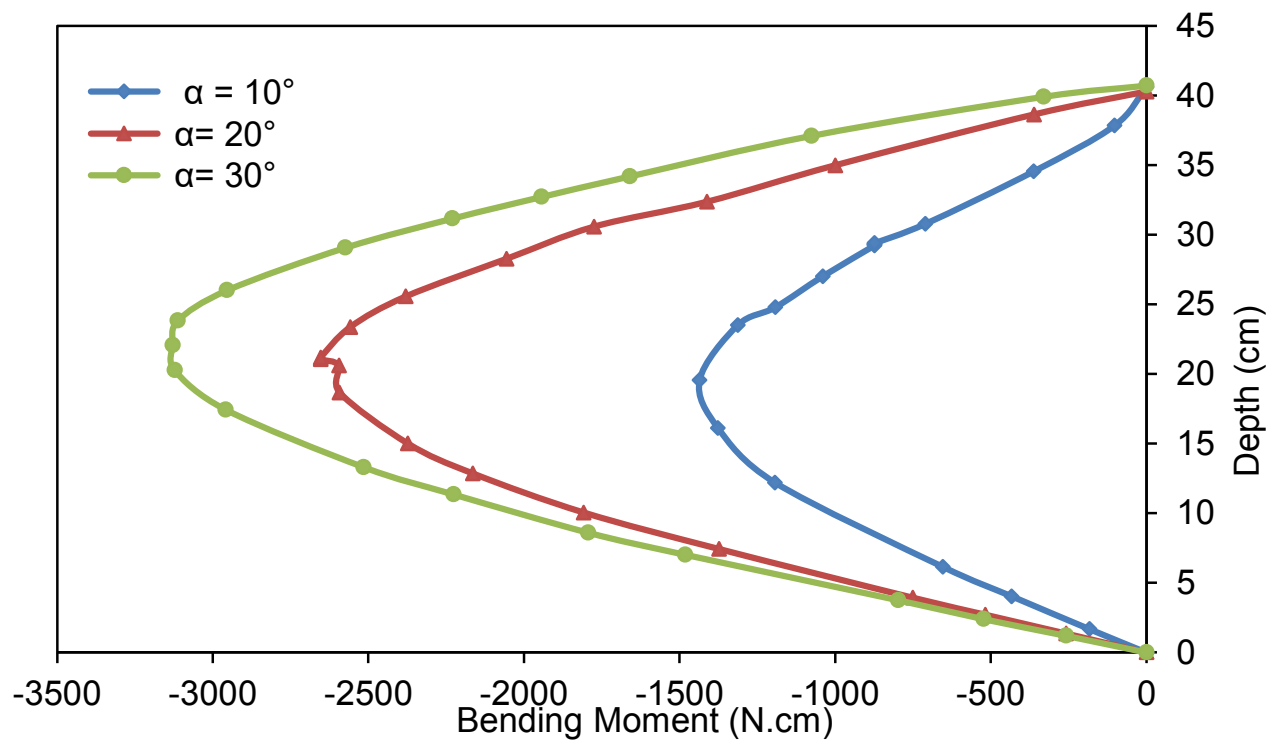

Figure 10.Bending moment distribution along a batter pile shaft for circular shape with batter angle and $\mathrm{L} / \mathrm{d}=20$.

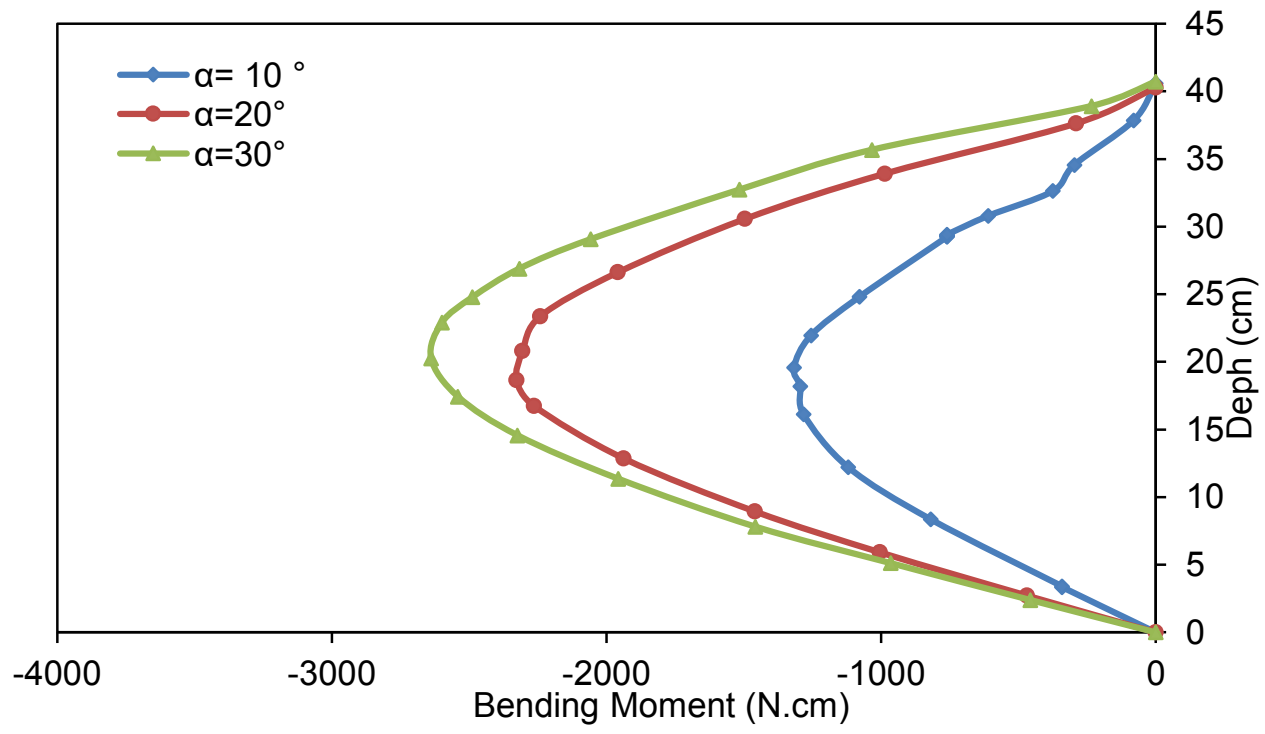

Figure 11. Bending moment distribution along a batter pile shaft for square shape with batter angle and $\mathrm{L} / \mathrm{d}=20$.

\section{Conclusions}

This paper included a three-dimensional analysis to investigate the influence of significant variables affecting vertical and batter pile behavior's pullout capacity under the axial pullout loading. The general findings may be outlined as follows:

- The relationship between the load and displacement is linear at the early stages of applying the axial pullout load, then transforms to the nonlinear. 
- The ultimate pullout load of the battered pile embedded in dry sandy soil increases with increasing of the inclination angle, and the greater values are marked at the batter angle equals $20^{\circ}$.

- The circular pile is more resistant to pullout loads than the square pile shape. The circular pile's pullout load increases about $2.8-6.1 \%$ at (L/D) equals 15 , and $4.3-8.5 \%$ at $\mathrm{L} / \mathrm{D}$ equals 20 more than square pile shape.

- The pile's embedment ratio has a significant impact on the values of a pullout load of a battered pile; the pullout capacity at $0.2 \mathrm{~cm}$ axial displacement is significantly increasing when the $\mathrm{L} / \mathrm{d}$ ratio increases.

- The batter pile pullout capacity in dense sandy soil increases with the increasing batter angle for square pile shape.

- All batter angles exhibit a single curvature shape of the bending moment profile. A circular pile model has a bending moment more than the square pile model, and in both models, the $\mathrm{L} / \mathrm{D}$ has a little effect on the values and distribution of bending moment.

- A bending moment's peak values are marked approximately at a midpoint of a battered pile, while a zero value is located at pile tip and pile head.

\section{References}

[1] Bose, K.K. and Krishnan, A., 2009. Pullout capacity of model piles in sand. Indian Geotechnical Society Chennai Chapter, Student Competition Paper, pp.49-54.

[2] Hanna, A.M. and Afram, A., 1986. Pull-out capacity of single batter piles in sand. Canadian Geotechnical Journal, 23(3), pp.387-392.

[3] Atici, M. A. 2009. 3-D Numerical model for pullout capacity of single batter pile in sand. Doctoral dissertation, Concordia University.

[4] Nazir, A. and Nasr, A., 2013. Pullout capacity of batter pile in sand. Journal of advanced research, 4(2), pp.147-154.

[5] Gaaver, K. E. 2013. Uplift capacity of single piles and pile groups embedded in cohesionless soil. Alexandria Engineering Journal, 52(3), 365-372.

[6] Hazzar, L., Hussien, M.N. and Karray, M. 2015. 3D modeling laterally loaded battered piles in sand. GeoQuebec.

[7] Al-Neami, M.A., Rahil, F.H. and Al-Bayati, K.S., 2020. February. Behavior of batter pile group models embedded in sandy soil under monotonic loading. In IOP Conference Series: Materials Science and Engineering, Vol. 737(1), p. 012088.

[8] Naveen, V., Arumairaj P. D., and Raman, S. J., 2019. model researchon oblique load carrying capacity of batter pile groups. International Journal of Innovative Technology and Exploring Engineering (IJITEE), 8(6S4).

[9] Sabbagh, T.T., Al-Salih, O. and Al-Abboodi, I., 2019. Experimental investigation of batter pile groups behaviour subjected to lateral soil movement in sand. International Journal of Geotechnical Engineering, 4(7), 705-716.

[10] Gebresilassie, W. T. 2020. Numerical Investigation of Single Batter pile Due to Inclined Loads. M.Sc. Thesis.

[11] Ekici, A. 2013. Three-dimensional finite element modelling for the laterally loaded passive pile behaviour. M.Sc. Thesis, Middle East Technical University.

[12] Al-Neami, M. A., Rahil, F. H., Al-Bayati, K. S. 2016. Bearing capacity of batter piles embedded in sandy soil. International Journal of Geotechnical Engineering, 10.5, 529-532.

[13] PLAXIS 3D Reference Manual (2020). 